\title{
Performance Analysis of LTE and IEEE 802.16 WiMAX in terms of Attenuation and BER via MATLAB: Scenario based ROF Amalgamation as Backhaul Technology
}

\author{
Hitesh Kumar \\ Department of Telecommunications \\ Mohammad Ali Jinnah University, Karachi
}

\begin{abstract}
The possibilities for fiber optics are nearly endless because they are flexible under extreme conditions and the signal do not distort easily. Wireless technology has introduced high speed internet accessibility through wireless broadband. Radio over fiber; the integration of microwave and optical networks is the potential solution for reducing cost in terms of equipment, running finance and capacity enhancement. Radio over fiber, a supreme technology for the amalgamation of wireless and wired environment, because it combines the best parameters of two mostly used communication technologies. The purpose of this paper is to analyze the performance of ROF as a backhaul technology when compared to the traditional optical fiber in wireless environments like LTE \& IEEE 802.16 WiMAX. Radio technology over optical fiber as a medium can prove to be the next generation solution. The analysis is then used to identify ROF feasibility as a backhaul technology for LTE and WiMAX. Optical and ROF network is deployed using MATLAB for acquiring the results through simulation to prove the hypothesis.
\end{abstract}

\section{Keywords}

ROF, Fiber Optics, Wireless Networks, LTE, WIMAX,

Service, Backhaul Technology.

\section{INTRODUCTION}

Optical fiber has higher carrying capacity, less expensive and contains less signal degradation due to which it is most widely used backbone technology. Radio over Fiber is an emerging technology and it provides cost effectiveness, large bandwidth utilization, better network services and capacity enhancement as the radio signals are carried out on the optical fiber in the form of light. Therefore RoF has grave importance in near future as the next generation backhaul technology for various heterogeneous networks. [1]

Following are the parameters that will be critically evaluated for the purpose of comparative study on currently implemented fiber with ROF over these heterogeneous networks. To make a cost effective solution in terms of equipment cost and running finance for backhaul technology, $\mathrm{RoF}$ is proposed as the replacement of optical fiber for wireless broadband networks. This paper is based upon the evaluation of Radio over fiber of specific parameters as mentioned below:

- Attenuation

- $\quad$ Bit Error Rate (BER)

\section{FIBER OPTIC}

Communication is a significant part of our everyday life. Every day we are using, diverse type of communication services, such as voice, video, images and data message. As Requirements of these services increases, demand for large transmission capacity networks also increases. In order to fulfill the increasing demands for higher data rate and larger bandwidth, light wave technology have been developed. [2] The combination of photons and glass fibers provide a tremendous transmission capability improvement compared to transmission lines through electrons and copper wires. As a result, fiber optical transmission is now widely deployed in the backbone network. Clearly, fiber optic transmission technology will remain the key communication technology for the foreseeable future.

The era of information revolution is upon us. The internet has brought up the world close together. The demand for high bitrate communication rate has heralded fiber-optic light wave communication system as the savior, primarily because of the extremely broad bandwidth associated with an optical carrier. [3] This is because the frequency of an optical carrier is five orders of magnitude greater than the frequency of a microwave carrier and since the modulation bandwidth is usually limited to a small fraction of the carrier frequency in digital systems, this translates to roughly 100,000 times more capacity for fiber optic communication.

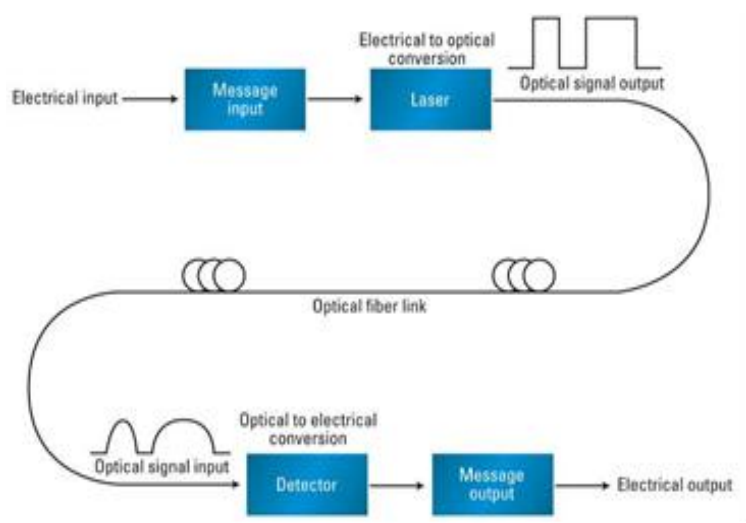

Fig1: Optical fiber communication system

\section{RADIO OVER FIBER}

Radio over fiber, a supreme technology for the amalgamation of wireless and wired environment, because it combines the best parameters of two mostly used communication 
technologies. The last mile user is free from direct physical connection to a network because of the wireless connection while optical networks provide approximately limitless bandwidth. Thus Radio over Fiber offers high bandwidth along with the mobility which is the need for both running and upcoming applications (i.e. High Definition TV, Video on Demand, 3D Television, video conferencing). Beside this, RoF networks also offer larger geographical flexibility for wireless and wired technologies.[4] High data rate for the applications such as multimedia services with low power and cost are the reasons for the combination of radio and physical connection networks using RoF. The amalgamation has the potential to make the networks crystal clear, active and quicker. The targeted applications of radio over fiber are cellular networks, wireless LAN (WLAN) at mm-wave bands, wireless broadband networks to road vehicle communication (RVC) networks for intelligent transportation system (ITS) [3].

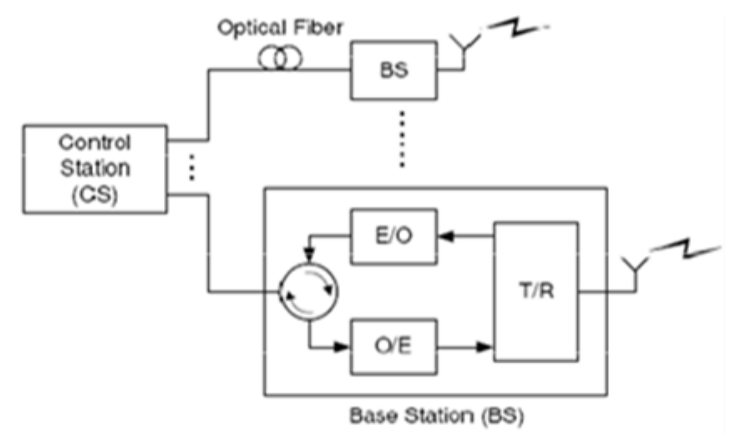

Fig2: General Radio Over Fiber System

\section{IEEE 802.16 WiMAX}

WiMAX is one of the most widely used broadband technologies nowadays in the world. WiMAX system delivers broadband services in an economical way both to enterprise and residential customers. [7] WiMAX an alternative to wire technologies like DSL, T1/E1, cable modems is a wireless version based on Ethernet standards. More, WiMAX is an industry organization formed by leading equipment and component companies for compatibility and interoperability of wireless broadband access system confirms to IEEE 802.16. WiMAX operates similar to $\mathrm{Wi}-\mathrm{Fi}$ but it provides greater distance coverage, high speed then Wi-Fi and can accommodate a large no of users. WiMAX can provide it services in an area difficult for wired connections to reach and also overcome the limitations the wired networks [8]. WiMAX formed in April 2001, operates in the frequency range of $10-66 \mathrm{GHz}$ under IEEE 802.16 specifications, supports up to $40 \mathrm{Mbps}$.

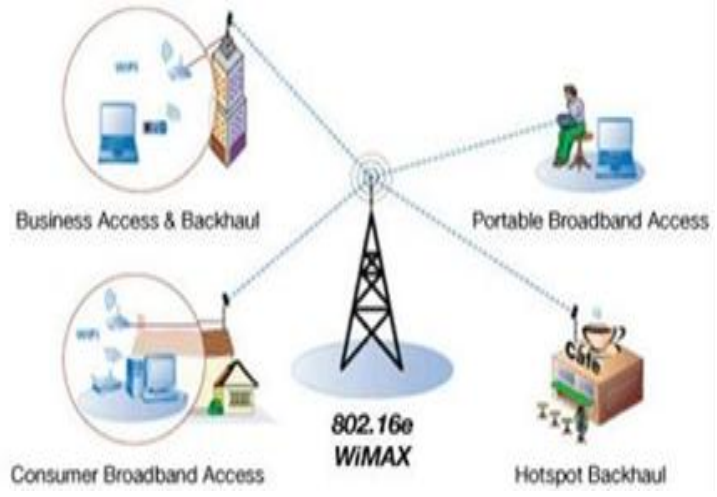

Fig3: WiMAX Network

\section{LONG TERM EVOLUTION (LTE)}

Mobile internet service for people when they are moving should be developed in such a way that it should meet the need of today's world. Mobile broadband is the best answer to satisfy the customer's demands by the help of the latest technologies like long term evaluation (lte) and worldwide interoperability for microwave access (WiMAX). Wireless technologies provided the voice services to the end users firstly; now, it is the time for data to be accessed wirelessly. Functions like emails, file downloading, video conferencing and chatting, and streaming are now available in the mobile sets. Mobile broadband is the technology which makes the commuter's idle time to be efficiently utilized. It provides users a direct connection to internet without being to a place where wired connection is present [5].

The mobile usage has increased rapidly over the decade. To enhance the absolute coverage, data services, data rates and service coverage at the cell boundaries, half way nodes called intermediate nodes are introduced. These nodes are placed in between UE (User Equipment) and Macro BS (Base Station), also include Micro, Pico and Femto cells. Relays are used instead of repeaters at the cell edges where the received SNR is very poor. These relays are for network extension; this extension may be temporary or permanent. By placing a relay on the behalf of intermediate nodes within the building or outside the building can amplify the received signals before being transferred to users [6].



Fig4: Data rates of different technologies

\section{ANALYSIS}

This section provide the analysis of Fiber optic and radio over fiber when implemented as a backhaul technology for the environments like LTE and WiMAX. The analysis is performed on the basis of two parameters i.e. Attenuation and BER. Simulator used to analyze Fiber optic and Radio over Fiber is MATLAB.

\subsection{Attenuation}

Attenuation is a general term that refers to any reduction in the strength of a signal. Attenuation occurs with any type of signal, whether digital or analog. Sometimes called loss, attenuation is a natural consequence of signal transmission over long distances. The extent of attenuation is usually expressed in units called decibels (dBs). 


\subsubsection{WiMAX Network}

The following equation is used to develop a graph for Attenuation in WiMAX when ROF works as backhaul technology.

Attenuation: $2 *\left(\right.$ datarate + wavelength $\left.{ }^{\wedge} 2\right)+2 *\left(\right.$ cld $\left.^{\wedge} 2\right)+c d+$ $\left(10 *\left(P 0 * d 1^{\wedge} 2\right)\right.$

In which:

Data rate is in bits per second

Wavelength in $\mathrm{nm}$

$\mathrm{Cld}=$ cladding diameter of fiber

$\mathrm{Cd}=$ core diameter of fiber

D1 $=$ refractive index difference of cladding

$\mathrm{Po}=$ laser pulse power in $\mathrm{mW}$.

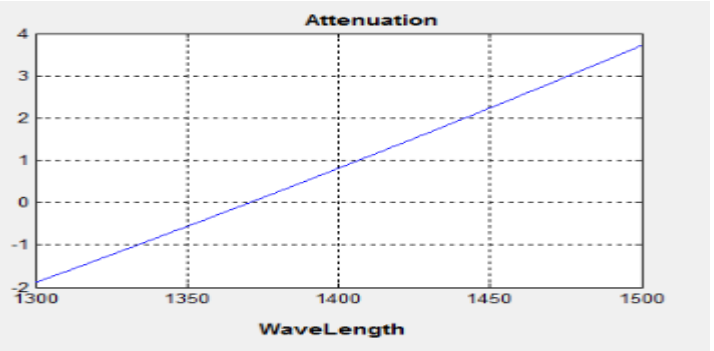

Fig5: Implementation of Attenuation of WiMAX in RoF environment

The graph in figure 5 shows the attenuation is increasing linearly with the increase in wavelength from $1300 \mathrm{~nm}$ to $1500 \mathrm{~nm}$ when RoF is implemented as backbone technology.

The following equation is used to develop a graph for Attenuation in WiMAX network when Fiber optic works as backhaul technology.

Attenuation: $\log$ (datarate + wavelength.$\left.^{\wedge} 2\right)+\sin ($ deltaz $) *$ (P0/Pin)

In which:

Deltaz $=$ split step length in $\mathrm{Km}$.

$\mathrm{Po}=$ laser pulse power in $\mathrm{mW}$.

Pin= input power

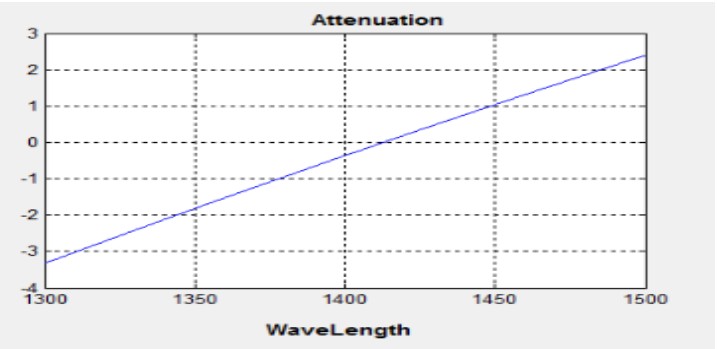

Fig6: Implementation of Attenuation of Fiber in WiMAX environment

The graph shows that attenuation is increasing from $-3 \mathrm{~m} / \mathrm{Km}$ to $2.5 \mathrm{~dB} / \mathrm{Km}$ with the increase in wavelength from $1300 \mathrm{~nm}$ to $1500 \mathrm{~nm}$ when the fiber is implemented as backbone technology for WiMAX.

\subsubsection{LTE Network}

The following equation is used to develop a graph for Attenuation in LTE when ROF works as backhaul technology.

Attenuation: $\log (n * L *$ datarate $)-2 *\left(\right.$ wavelength. $\left.^{\wedge} 2\right)+1 / P 0$ $P o=$ laser pulse power in $\mathrm{mW}$.

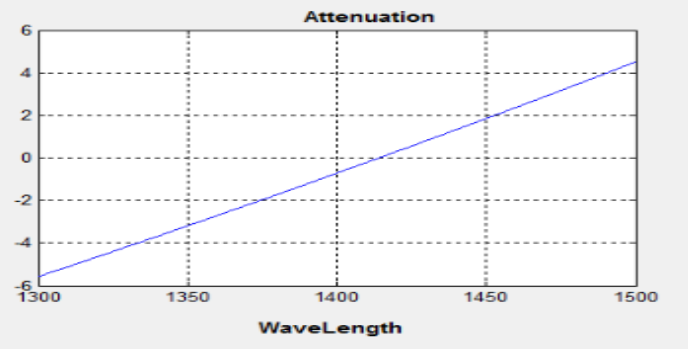

Fig 7: Implementation of Attenuation of ROF in LTE environment

The graph in figure 7 shows that the attenuation of RoF in case of LTE is increasing from $-4 \mathrm{~dB}$ to $4 \mathrm{~dB} / \mathrm{Km}$ as wavelength is increasing from $1300 \mathrm{~nm}$ to $1500 \mathrm{~nm}$.

The following equation is used to develop a graph for Attenuation in LTE when Optical Fibers works as backhaul technology.

Attenuation: $\log (n * L *$ data_rate + Fiberstream $)+N A+c+2 *$ (wavelength. $\wedge$ ) + iterations

In which:

$\mathrm{NA}=$ Numerical Aperture

$\mathrm{C}=$ Speed of light $\mathrm{n}=$ refractive index of the fiber optic $\mathrm{L}=$ Length of fiber optics in $\mathrm{Km}$. Iteration $=\mathrm{L} /$ deltaz

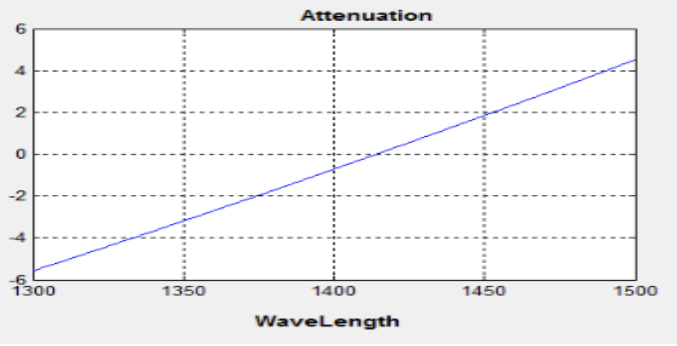

Fig 8: Implementation of Attenuation of Fiber in LTE environment

The graph in figure 8 shows that the attenuation of Fiber in case of LTE increases from $-6 \mathrm{~dB}$ to $6 \mathrm{~dB} / \mathrm{Km}$ as wavelength is increasing from $1300 \mathrm{~nm}$ to $1500 \mathrm{~nm}$

Overall the signal attenuation in case of ROF is less than fiber optic when implemented as backhaul technology for LTE environment. 


\subsection{Bit Error Rate (BER)}

The bit error rate (BER) is the percentage of bits that have errors relative to the total number of bits received in a transmission, usually expressed as ten to a negative power.

\subsubsection{WiMAX Network}

Equation used to implement bit error rate (BER) of WiMAX in RoF environment is:

BER: $\log ($ data rate + ROFstream $) *(P O+N A)+(1 /$ Pin $)$

In which:

\section{Pin= input power}

$\mathrm{NA}=$ Numerical Aperture

$\mathrm{Po}=$ laser pulse power in $\mathrm{mW}$.

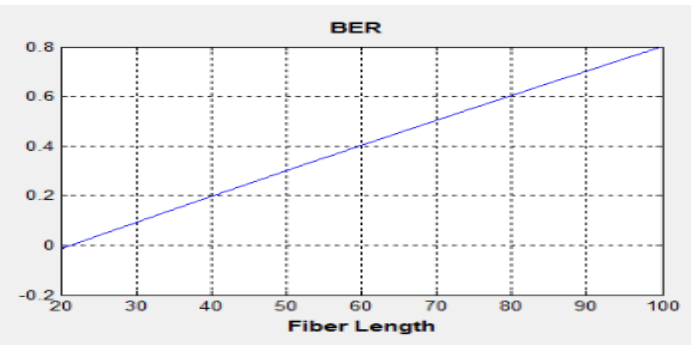

Fig 9: BER of ROF in WiMAX environment

The graph in figure 9 shows that BER of WiMAX increases linearly with the increase in fiber length when ROF is implemented as backhaul technology.

Equation used to implement bit error rate (BER) of WiMAX in traditional Optical Fiber environment is:

\section{BER: $\sin ($ wavelength $)+\tan ($ datarate-ROF stream $)+L$ $+N A+c l d$}

In which:

$\mathrm{L}=$ Length of fiber optics in $\mathrm{Km}$.

$\mathrm{NA}=$ Numerical Aperture

$\mathrm{Cld}=$ cladding diameter of fiber

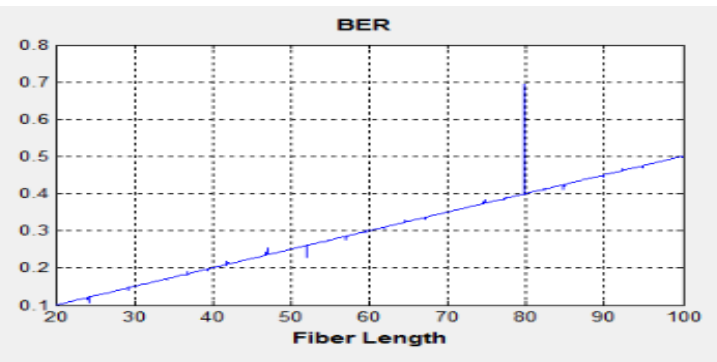

Fig 10: BER of Fiber in WiMAX environment

The graph in figure 10 shows that BER of WiMAX when implementing fiber as backbone technology is increasing and fluctuating at certain fiber lengths

Overall the graphs show that fiber optic has less BER than ROF as backhaul technology in case of WiMAX environment.

\subsubsection{LTE Network}

The following equation is used to implement BER of ROF in LTE environment

BER: $\log ($ datarate + ROF stream $) *\left(P 0+P i n+c^{\wedge} 2\right)+\left(1 / r 0^{*} n 2\right)$

In which:

Pin= input data rate

$\mathrm{C}=$ Speed of light

$\mathrm{n} 2=$ nonlinear index coefficient in $\mathrm{m}^{\wedge} 2 / \mathrm{W}$

$\mathrm{Po}=$ laser pulse power in $\mathrm{mW}$.

$\mathrm{r} 0=$ fiber spot size $\mathrm{m}^{\wedge} 2$

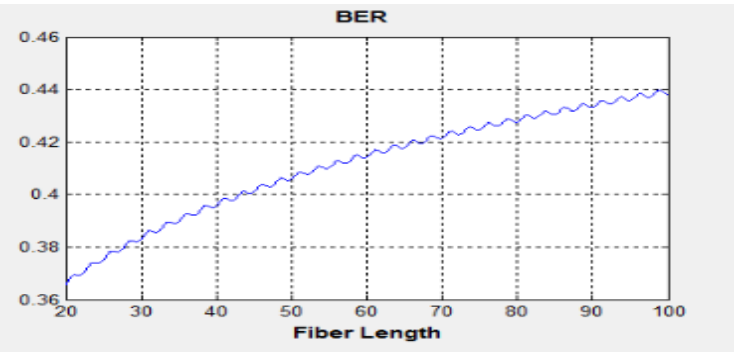

Fig 11: BER of LTE when ROF as backhaul technology

The graph shows that BER of LTE is increasing from $0.35 \mathrm{~dB}$ to $0.46 \mathrm{~dB}$ with the increase in fiber length from 20 to $100 \mathrm{Km}$ when RoF is implemented as backbone.

The following equation is used to implement BER of Optical Fiber in LTE environment: equation is used to develop a graph for capacity in Ethernet network when radio over fiber works as backhaul technology.

BER: $\sin ($ wavelength $)+\log (n *$ data rate + FibeRstream $) *$ $(P 0+P i n)+(1 / r 0 * n 2)$

In which:

$\mathrm{n}=$ refractive index of fiber $\mathrm{Po}=$ laser pulse power in $\mathrm{mW}$. Pin= input power $\mathrm{r} 0=$ fiber spot size $\mathrm{m}^{\wedge} 2$

Fig12: BER of Fiber in LTE environment

The graph in figure 12 states that BER of LTE is fluctuating

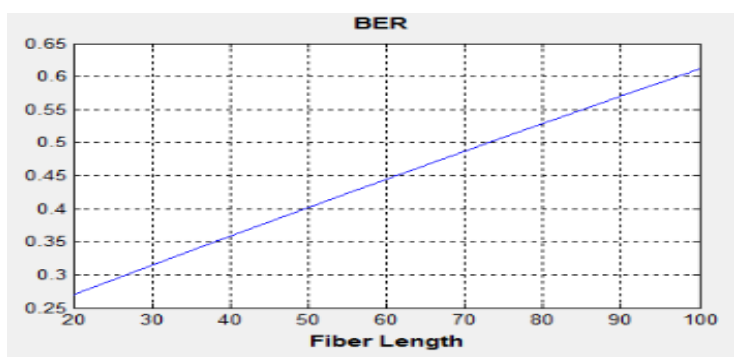

increasing with the increase in fiber length when fiber is implemented as backhaul technology.

ROF provides less BER in case of LTE compare to fiber as backhaul technology. 
Table 1: Result based proposition for cellular \& Ethernet environment

\begin{tabular}{|c|c|c|}
\hline Paramater & WiMAX & LTE \\
\hline Attenuation & $\begin{array}{c}\text { Traditional } \\
\text { Fiber }\end{array}$ & $\begin{array}{c}\text { Radio over } \\
\text { Fiber }\end{array}$ \\
\hline Bit Error Rate & $\begin{array}{c}\text { Traditional } \\
\text { Fiber }\end{array}$ & $\begin{array}{c}\text { Radio over } \\
\text { Fiber }\end{array}$ \\
\hline
\end{tabular}

Table 1 shows the simulated results of comparison between ROF and traditional fiber optics, the results in terms of parameters i.e. Attenuation and bit error rate stated that ROF gives better performance in LTE environment while in case of WiMAX, traditional fiber gives better performance than RoF.

\section{CONCLUSION}

ROF and fiber optic are implemented as the backhaul technology for various heterogeneous networks but for the purpose of this thesis, WiMAX and LTE were chosen. These two heterogeneous networks are evaluated over ROF and traditional fiber on the basis of Attenuation, Bit Error Rate and Carrier to Noise Ratio with the help of MATLAB. Following was concluded for aforementioned parameters;

\section{Attenuation}

The simulated results show that overall Signal attenuation in fiber optic is less than ROF as backhaul technology in case of WiMAX environment while in the case of LTE the signal attenuation is less in ROF then traditional fiber optics network.

\section{Bit Error Rate (BER)}

It is concluded from the graphs that that fiber optic has less BER than ROF as backhaul technology in case of WiMAX environment while RoF provides less BER in case of LTE compare to fiber as backhaul technology.

Based on the results and analysis of the given parameters via MATLAB simulation, it is concluded that ROF is a feasible alternative to the traditional fiber for various heterogeneous network, and especially for LTE. Depending on the nature and specific purpose of the network, bit error rate and carrier to noise ration contains the key to selection of technology for the network. Future expansion and unforeseen requirements of the users should be considered while deciding upon the backhaul link as attenuation of the network can add cost.

The author has evaluated $\mathrm{RoF}$ as an alternate solution for wireless broadband networks for end to end propagation path. The design and a network model of wireless broadband network have been implemented with RoF as the backbone technology over MATLAB. The future work will include the design, prototype and deployment of wireless broadband networks with RoF as the backbone technology.

And also to identify what are the reasons that $\mathrm{RoF}$ is not performing better in case of WiMAX environment.

\section{REFERENCES}

[1] Jung Huyn Lee, "Radio over Fiber as a cost effective technology for transmission of WiMAX", World Academy of Science, Engineering and Technology, PP 424-429, 2009

[2] R. Karthikeyan and S. Prakasam, "A Survey on Radio over Fiber (RoF) for wireless broadband access technologies", International Journal of Computer Applications (0975-8887), Volume 64-No.12, February 2013.

[3] M. Zin, M. S Bongsu, S. M. Idrus, and N. Zulkifli, "An Overview of Radio-over-Fiber Network Technology", IEEE/Journal of Light Wave Technology, 2010

[4] H.B.Kim, "Radio over fiber based network architecture", IEEE proceedings in Opto electronics, vol.143, October 2005.

[5] H. Al Raweshidi, S. Komaki, "Radio Over fiber Technologies for Mobile Communications Network". Artech House, London, eds. 2002.

[6] O.Tipmongkolsilp, S.Zaghloul and A.Jukan, "The evolution of cellular backhaul technologies: Current issues and future technologies", IEEE communications surveys and Tutorials, vol.13, no.1, PP 97-113, First quarter 2011.

[7] Riegel M,"Ethernet services over mobile Wimax" IEEE journals and magzines, Vol.46, 2008.

[8] M.GarciaLarrode and AMJ.Koonen, "Towards a reliable RoF infrastructure for broadband wireless access".IEEE proceedings symposium, 2006. 